Research Article

\title{
Study on the Vibration Mitigation Characteristic of Dual Clearance Squeeze Film Damper
}

\author{
Zhaojun Feng $\mathbb{D}^{1},{ }^{1}$ Guihuo Luo $\left(\mathbb{D},{ }^{1}\right.$ Hai Yang, ${ }^{2}$ Wangqun Deng, ${ }^{2}$ Wei Chen, ${ }^{1}$ Nan Zheng $\left(\mathbb{D},{ }^{1}\right.$ \\ Xuemin Liao, ${ }^{1}$ and Lijia Chen ${ }^{1}$ \\ ${ }^{1}$ College of Energy and Power Engineering of Nanjing University of Aeronautics and Astronautics, \\ Key Laboratory of Jiangsu Aviation Powerplant, Nanjing 210001, China \\ ${ }^{2}$ AECC Hunan Aviation Powerplant Research Institute, Key Laboratory of Aero-engine Vibration Technology, \\ Aero Engine Corporation of China, Zhuzhou 412002, China
}

Correspondence should be addressed to Guihuo Luo; ghluo@nuaa.edu.cn

Received 13 January 2021; Accepted 26 April 2021; Published 7 May 2021

Academic Editor: Jean-Jacques Sinou

Copyright (C) 2021 Zhaojun Feng et al. This is an open access article distributed under the Creative Commons Attribution License, which permits unrestricted use, distribution, and reproduction in any medium, provided the original work is properly cited.

In this paper, a novel model of dual clearance squeeze film damper (DCSFD) was constructed considering convection effect and the vibration mitigation characteristic of DCSFD was researched. The DCSFD film force linearity $r_{\mathrm{FSFD}}$ was proposed. The response characteristics of rigid rotor containing DCSFD were studied based on the DCSFD model. A response experiment of the DCSFD was arranged, and the model was verified. A good consistence was achieved between the simulation and experiment. The experiment and simulation result manifests that the unbalance response of DCSFD was smaller than that of SFD at every excitation frequency. The DCSFD could inhibit the nonlinear vibration such as the bistability and bifurcation due to big mass eccentricity, and nonlinear film force for the DCSFD film force linearity was bigger than that for SFD. The thickness ratio of inner and outer film, pressure loss coefficient, and inner film thickness were the important parameters that have great influence on DCSFD vibration mitigation characteristic.

\section{Introduction}

Recently, there has been growing interest in the dynamic characteristics of rotor system with nonlinear film force from the novel squeeze film damper such as the magnetorheological SFD (MHSFD), two-lobe wave SFD, the DCSFD, and so on. The key point of modeling the rotor system with novel SFD is modeling the nonlinear film force under different journal eccentricities. For the rotor-SFD system, the analytical expression of SFD film force could be obtained through the short bearing assumption and the model of film force of the novel SFD has been gradually improved in recent years.

J.A. Friedericy proposed the floating ring squeeze film damper in 1965. The film of SFD was divided by the two floating rings into three film layers. The traditional SFD would become ineffective and failure when there is a big unbalance load in the rotor system. This problem was solved to a certain degree by the floating ring squeeze film damper [1]. David P. Fleming proposed and patented the DCSFD in 1984. The film in SFD was divided into two layers by a sleeve, which was constrained by a shear pin. The outer film would be activated under high unbalance conditions. The DCSFD was different from the floating ring squeeze film damper proposed by J.A. Friedericy; for the latter, the floating ring was floating in the film freely [2-4]. Based on DCSFD proposed by the David P. Fleming, Moraru L and Keith T. G. modeled the single SFD and the DCSFD while the sleeve was released and both the inner and outer films were activated. A rotor test rig was designed. The simulation model was verified by the experimental result [5-7]. Ertas B. H. and Camatti M. managed a test about the unbalance response of a rotor supported on a damped gas bearing. The tested result manifested that the gas bearing was capable of bearing the severe imbalance loading [8]. M. A. Rezvani and E. J. Hahn put forward the DCSFD, which with a spring support for the 
floating ring, except for the squirrel cage for the rotor journal. The simulation model of the rotor-DCSFD system was deduced, and the nonlinear dynamic characteristics were researched such as the bistable jump and aperiodic response. The conclusion shows that the response largely depended on the support stiffness and the mass of the floating ring [9]. Hailun Zhou deduced the Reynolds equation of the inner and outer film of DCSFD, and the film force and pressure distribution was received. From the dynamic response of the rotor-DCSFD system obtained by simulation and experiment, Zhou concluded that the DCSFD improved the nonlinear characteristics and suppressed the bistable characteristic of the rotor-SFD system, but the film force was constructed without distinction of the radial and circumferential film force [10-12].

The characteristic of the rigid and flexible rotor supported on the traditional squeeze film damper also attracts the attention of many experts and scholars.

Sung-Hwa Jeung and Luis San Andres obtained the SFD film stiffness and damping and inertial coefficients through the bidirectional exciting test [13]. Jiyan Wang built the rotor-SFD-Sling bearing system and analyzed the characteristics from periodic whirling to chaos based on the Runge-Kutta method [14]. Mostafa and Abdolreza Ohadi Irannejad investigated the dynamic characteristic of a rotor supported on a novel SFD: MHSFD, and Mostafa Irannejad concluded that the rotor could avoid to be destroyed by controlling the electric current [15]. Geraldo Creci and Jose Orlando Balastrero did a research to obtain the optimum SFD clearance by analyzing the transient response of the rotor-SFD system [16]. Jaroslav Zapomel investigated the vibration attenuation characteristics of MHSFD by constructing a novel model of MHSFD based on the bilinear oil presentation [17]. Zhong Luo did a research about the nonlinear characteristics of a rotor-SFDB system which took the nonlinear bearing force into consideration [18]. Giovanni Adiletta modeled the film force of a new kind of SFD with a lobe geometry in the bearing bore and concluded that the lobe could greatly influence the response of the rotor system $[19,20]$. Li Yan and Liao Mingfu found that the SFD concentricity could reduce the rotor vibration amplitude while increasing the risk of nonlinear vibration [21]. Huizheng Chen and Lei Hou detected the relation between the rotor jump phenomenon and the rotor-SFD parameters, and Chen concluded that reasonable combination of parameters could help the rotor-SFD system to avoid the harmful nonlinear vibration [22]. Inayat-Hussain researched the effect of the design parameters on the nonlinear behavior of the rotor-SFDB system, the result showed that the nonlinear behavior of rotor was caused not only by the nonlinear force of the bearing but also by the design parameters [23]. Adolfo Delgado tested the force coefficient of a squeeze film damper with a mechanical seal, which could eliminate the leakage of the squeeze film damper and strengthen the performance of vibration of squeeze film damper [24]. A. Bouzidane and M. Thomas proposed a nonlinear model of a rigid rotor supported on a three-pad SFD, which could reduce the cost [25]. They also concluded that it was effective to monitor the electric field and fluid viscosity for controlling the vibration of the flexible rotor [26]. Bonello and Pham did a research about two nonlinear unbalanced rotors coupled with a squeeze film damper, and a fast computation method was verified [27]. Aydin Boyaci applied the numerical continuation method to study the nonlinear vibration of the rotor-bearing system [28]. Zhao L. and Liao M. constructed the film force of the elastic ring squeeze film damper (ERSFD), and the rotor system containing ERSFD was build based on which the unbalance response of the rotor was researched [29].

However, few attention was focused on modeling DCSFD considering the convection effect and film thickness ratio and studying the vibration mitigation characteristic of DCSFD, with which a better guidance could be obtained for engineering design of DCSFD. The purpose of this research was to further investigate the modeling method of DCSFD, based on which, the dynamic characteristic of the rotorDCSFD system was researched. The mechanism of vibration mitigation for DCSFD was investigated. The DCSFD focused in this paper was different from the DCSFD proposed by David P. Fleming and the floating ring SFD developed by J. A. Friedericy. In this research, the film ring was divided into two film layers by the floating ring, which was floating freely in the film.

\section{Modeling of DCSFD}

The structure diagram of DCSFD is shown in Figure 1; the film was divided into two layers (the inner film and the outer film) by the floating ring; the inner and outer film force acted on the floating ring simultaneously. Assuming that the floating ring and the journal were whirling with the same frequency and whirling by the circular orbit, then the force analysis for the floating ring is shown in Figure 2.

In Figure 2, $F_{r 1}$ and $F_{t 1}$ were the inner radial and circumferential force, respectively, and $F_{r 2}$ and $F_{t 2}$ were the outer radial and circumferential force, respectively.

The inner and outer film force provides the centripetal force for whirling of floating ring, and based on Newton's second law, the differential motion equation of the floating ring could be obtained as shown in the following equations:

$$
\begin{gathered}
F_{t 1} \cos \left(\theta-\frac{\pi}{2}\right)-F_{t 1} \cos \left(\theta-\frac{\pi}{2}\right)+F_{r 2}=m_{f} \Omega^{2} e_{2}, \\
F_{t 1} \sin (\pi-\theta)+F_{t 1} \sin \left(\theta-\frac{\pi}{2}\right)=F_{t 2},
\end{gathered}
$$

where

$$
\begin{aligned}
& F_{r 1}=\int_{-L_{f} / 2}^{L_{f} / 2} \int_{0}^{2 \pi} p_{1}\left(\theta_{1}, Z\right) R_{1} \mathrm{~d} \theta_{1} \mathrm{~d} Z \cos \theta_{1}, \\
& F_{t 1}=\int_{-L_{f} / 2}^{L_{f} / 2} \int_{0}^{2 \pi} p_{1}\left(\theta_{1}, Z\right) R_{1} \mathrm{~d} \theta_{1} \mathrm{~d} Z \sin \theta_{1},
\end{aligned}
$$




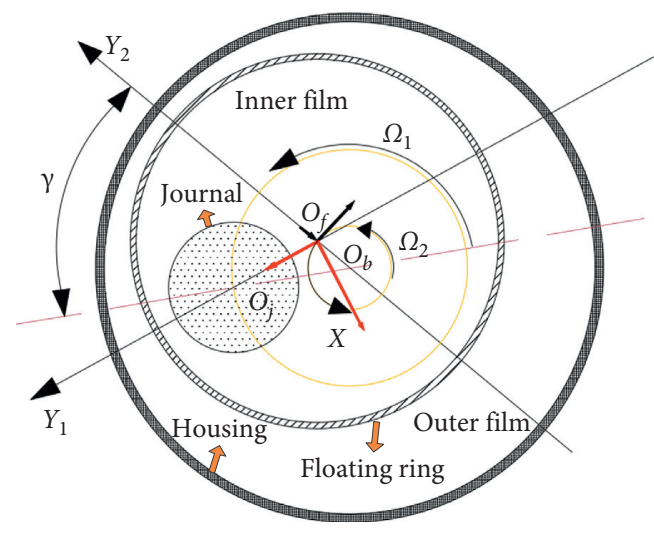

FIgURE 1: DCSFD structure scheme.

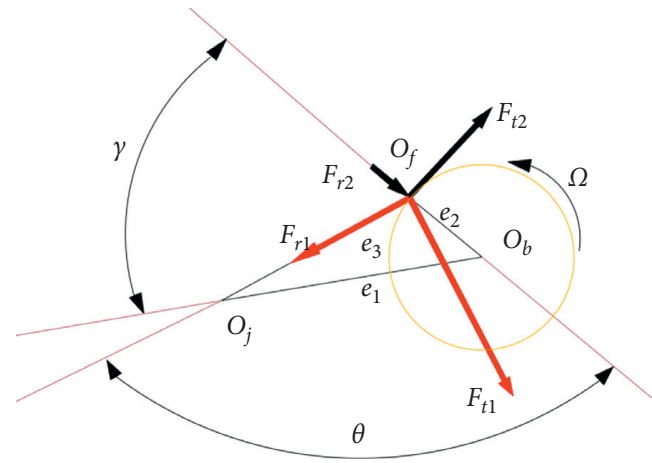

Figure 2: Force diagram for floating ring.

$$
\begin{aligned}
& F_{r 2}=\int_{-L_{f} / 2}^{L_{f} / 2} \int_{0}^{2 \pi} p_{2}\left(\theta_{2}, Z\right) R_{2} \mathrm{~d} \theta_{2} \mathrm{~d} Z \cos \theta_{2}, \\
& F_{t 2}=\int_{-L_{f} / 2}^{L_{f} / 2} \int_{0}^{2 \pi} p_{2}\left(\theta_{2}, Z\right) R_{2} \mathrm{~d} \theta_{2} \mathrm{~d} Z \sin \theta_{2} .
\end{aligned}
$$

$p_{1}\left(\theta_{1}, Z\right)$ and $p_{2}\left(\theta_{2}, Z\right)$ were the pressure distribution of the inner and outer film, respectively, which were controlled by the Reynolds equation. Since the width of the floating ring was slightly less than the width of the film clearance inevitably, in this way, there are two clearances between the floating ring and the end seal ring, as shown in Figure 3. The clearance was named as the convection clearance. The inner and outer film would flow into the convection clearance, resulting in a certain pressure loss, as shown in Figure 3. For the end seal ring, some vapor cavitation would appear in the negative pressure region; however, the film is the continued two phase flow instead of the cavitated region.

The inner and outer Reynolds equations of DCSFD were shown in the following equations:

$$
\begin{aligned}
& \frac{1}{R_{1}^{2}} \frac{\partial}{\partial \theta_{1}}\left(h_{1}^{3} \frac{\partial p_{1}}{\partial \theta_{1}}\right)+\frac{\partial}{\partial Z}\left(\frac{h_{1}^{3}}{\eta_{1}} \frac{\partial p_{1}}{\partial Z}\right)=-12 \Omega_{1} \mu \frac{\partial h_{1}}{\partial \theta_{1}}, \\
& \frac{1}{R_{2}^{2}} \frac{\partial}{\partial \theta_{2}}\left(h_{2}^{3} \frac{\partial p_{2}}{\partial \theta_{2}}\right)+\frac{\partial}{\partial Z}\left(\frac{h_{2}^{3}}{\eta_{2}} \frac{\partial p_{2}}{\partial Z}\right)=-12 \Omega_{2} \mu \frac{\partial h_{2}}{\partial \theta_{2}},
\end{aligned}
$$

$$
\begin{aligned}
& h_{1}=C_{1}\left(1+\varepsilon_{3} \cos \theta_{1}\right), \\
& h_{2}=C_{2}\left(1+\varepsilon_{2} \cos \theta_{2}\right),
\end{aligned}
$$

where $\eta_{1}$ and $\eta_{2}$ were the pressure loss coefficients of the inner and outer film. From simple deduction, the following equation could be obtained:

$$
0<\eta_{1}=\eta_{2}<1
$$

Let

$$
\eta_{1}=\eta_{2}=\eta
$$

because the pressure loss was too complex to be theoretically analyzed. In this paper, $\eta$ was obtained based on the empirical value.

The inner film force was obtained by relative eccentricity $\varepsilon_{3}$, which was the real eccentricity producing inner film pressure. The outer film force was obtained by the outer eccentricity $\varepsilon_{2}$. The relationship between $\varepsilon_{1}$, $\varepsilon_{2}$, and $\varepsilon_{3}$ was shown in the following equation:

$$
\varepsilon_{3}^{2}=\varepsilon_{1}^{2}+\frac{\varepsilon_{2}^{2}}{r_{t}^{2}}-\frac{2 \varepsilon_{1} \varepsilon_{1} \cos \gamma}{r_{t}},
$$

where $r_{t}$ was the thickness ratio of the inner and outer layer film and $\gamma$ was the phase difference between the journal and the floating ring.

In this paper, the motion equation of the floating ring was solved iteratively based on the genetic algorithm, and the numerical solution was fitted to obtain the relationship between the inner film force of DCSFD and the inner eccentricity and the relationship between the inner and outer eccentricity, and then the simulation model of rotor supported on the DCSFD could be constructed.

\section{The Linearity of DCSFD Film Force}

Based on the numerical solution of equations (1) and (2), the approximate linear relationship between $\varepsilon_{1}, \varepsilon_{2}$, and $\varepsilon_{3}$ could be fitted, which was shown in the following equations:

$$
\begin{aligned}
& \varepsilon_{2}=k_{2} \varepsilon_{1}, \quad\left(0<k_{2}<1\right), \\
& \varepsilon_{3}=k_{3} \varepsilon_{1}, \quad\left(0<k_{2}<1\right) .
\end{aligned}
$$

The simulation results show that both $k_{2}$ and $k_{3}$ were only influenced by $r_{t}$, while $\eta$ has great influence on pressure and film force but little influence on $k_{2}$ and $k_{3}$, and the numerical relationship between $k_{2}, k_{3}$, and $r_{t}$ could be achieved by numerical results shown in the following equations:

$$
\begin{aligned}
& k_{2}=0.08097 r_{t}^{2}-0.0481 r_{t}+0.8195, \\
& k_{3}=-0.407 r_{t}^{2}+1.562 r_{t}-0.6723 .
\end{aligned}
$$

The parameters of DCSFD designed in this article are as follows: 


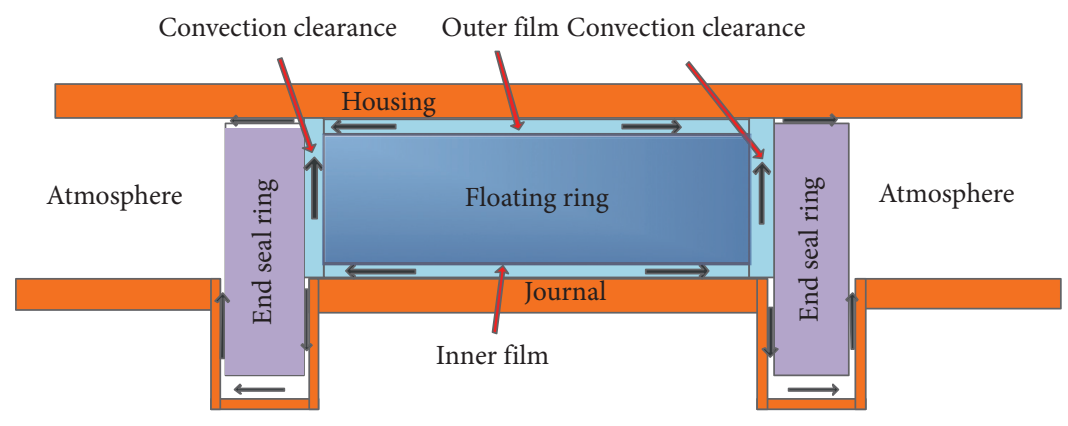

(a)

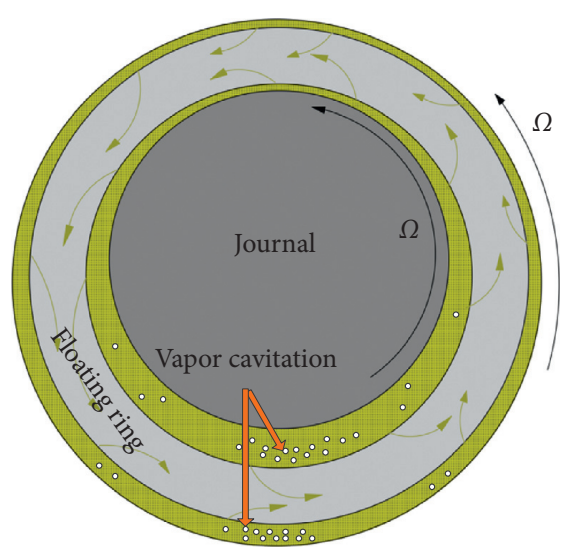

(b)

FIgURE 3: Schematic diagram for DCSFD convection: (a) front; (b) size.

$L=12.5 \mathrm{~mm}, \quad C_{2}=0.16 \mathrm{~mm}, \quad R=39 \mathrm{~mm}, \quad \rho=997.5$ $\mathrm{kg} / \mathrm{m}^{3}$, and $\mu=0.0598$ Pas.

All DCSFD film characteristic parameters correspond to the inlet oil temperature $27^{\circ} \mathrm{C}$. The relationship curve between DCSFD and SFD film force with $\varepsilon_{1}$ is shown in Figure 4.

Figure 4 indicates that under different $\varepsilon_{1}$, the film force of DCSFD was smaller than SFD, which means that DCSFD could effectively reduce the load of the journal passed to the supporting component, making the carrying capacity of the supporting part stronger; the linearity of DCSFD film force was better than SFD, the existence of floating ring strengthens DCSFD film force linearity, and the linearity of the film force of the support component could greatly affect the stability of the rotor system. This makes the rotorDCSFD system more stable. The shadow part in Figure 4 expresses the energy consumed by the whirling of floating ring.

In order to be able to quantify the linearity of DCSFD film force for deeper research, the circumferential and radial film force linearity was taken into account to contribute to DCSFD film force linearity, and a new parameter was proposed, that is, the DCSFD film force linearity $r_{\text {FSFD }}$, which was defined as the following equation:

$$
r_{\mathrm{DCSFD}}=\frac{\overline{F_{r}}}{\overline{F_{r}}+\overline{F_{t}}} r_{F_{r}}+\frac{\overline{F_{t}}}{\overline{F_{r}}+\overline{F_{t}}} r_{F_{t}},
$$

where $r_{F_{r}}$ and $r_{F_{t}}$ were the linearity of radial and circumferential forces, which could be obtained through linear regression theory, shown in the following equation:

$$
\left\{\begin{array}{l}
r_{F_{r}}=\frac{\sum_{i=1}^{n} \varepsilon_{i} F_{r i}-n \overline{F_{r}} \bar{\varepsilon}}{\sqrt{\left(\sum_{i=1}^{n} \varepsilon_{i}^{2}-n \bar{\varepsilon}^{2}\right)\left(\sum_{i=1}^{n} F_{r i}^{2}-n \bar{F}_{r}^{2}\right)}}, \\
r_{F_{t}}=\frac{\sum_{i=1}^{n} \varepsilon_{i} F_{t i}-n \overline{F_{t}} \bar{\varepsilon}}{\sqrt{\left(\sum_{i=1}^{n} \varepsilon_{i}^{2}-n \bar{\varepsilon}^{2}\right)\left(\sum_{i=1}^{n} F_{t i}^{2}-n \bar{F}_{t}^{2}\right)}},
\end{array}\right.
$$

where $\mathrm{n}$ was the number of eccentricity measure points.
Set the SFD with the same thickness as the inner film of DCSFD as the control group. Figure 5 shows that the curvature of curve $F-\varepsilon_{1}$ was changed with $r_{t}$. The effect of $r_{t}$ on DCSFD linearity was large.

Table 1 shows that the DCSFD linearity was bigger when $r_{t}=0.75$, which means that there is an optimal value of $r_{t}$. When $r_{t}=0.5$, DCSFD linearity dropped to 0.9726 , less than SFD, and the value of $r_{t}$ was obviously unreasonable, so there should be $r_{t}>0.5$. While $r_{t}=2, r_{\mathrm{DCSFD}}=r_{\mathrm{SFD}}$, which means that the inner film thickness was too big relative to outer film, DCSFD nearly turned to be a SFD, and the floating ring could not regulate the film pressure distribution, so there should be $r_{t}<2$.

$r_{t}$ should be in the range of $0.75-1.25$ to get the reasonable linearity of the DCSFD film force.

\section{The Comparison of Vibration Mitigation Characteristic for DCSFD and SFD}

The symmetrical rigid rotor, shown in Figure 6, without considering the gyro torque and the characteristic of flexible rotor was equipped with DCSFD and squirrel cage at both journals. Deep groove ball bearing was installed at one end, and cylindrical roller bearing was installed at the other end.

The journal force schematic of the rigid rotor is shown in Figure 7.

In Figure $7, F_{t 1}$ and $F_{r 1}$ were the circumferential and radial film forces, respectively. $F_{e}=m_{e} \omega^{2} e_{m}$ was the unbalanced excitation, and $F_{j}=m_{j} \omega^{2} e_{3}$ was the centrifugal force for journal, where $e_{1}=C_{1} k_{13} \varepsilon_{1} . F_{c}=c \omega e_{3}, F_{k}=k e_{3}$, and $e_{3}=k_{13} e_{1}$.

The circumferential force balance equation was shown in the following equation:

$$
F_{r 1}+F_{k}-F_{j}=F_{e} \cos \varphi
$$

The circumferential force balance equation was shown in the following equation:

$$
F_{t}+F_{c}=F_{e} \sin \varphi .
$$




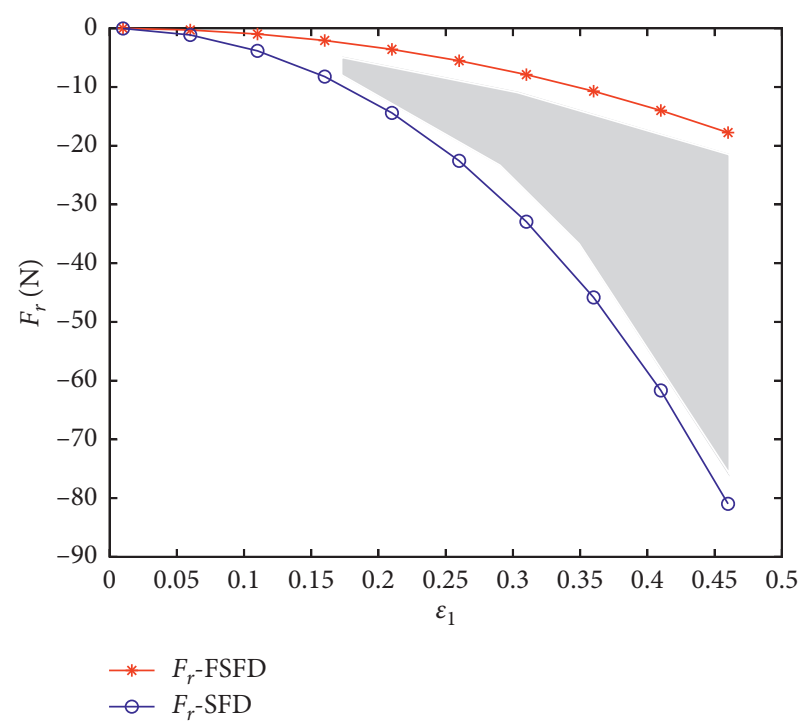

(a)

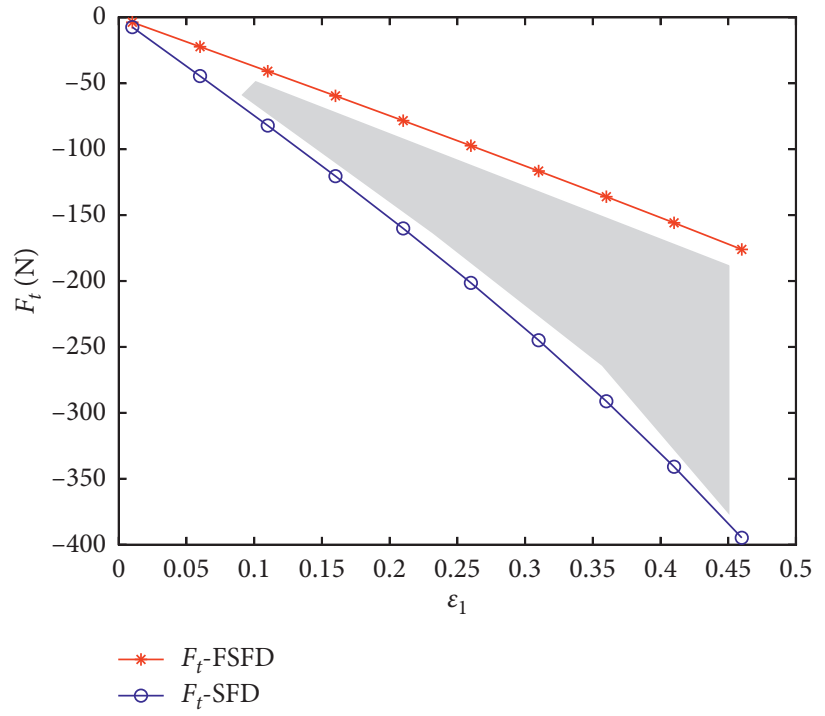

(b)

FIGURE 4: Film force vs. $\varepsilon_{1}$ : (a) radial film force; (b) circumferential film force.

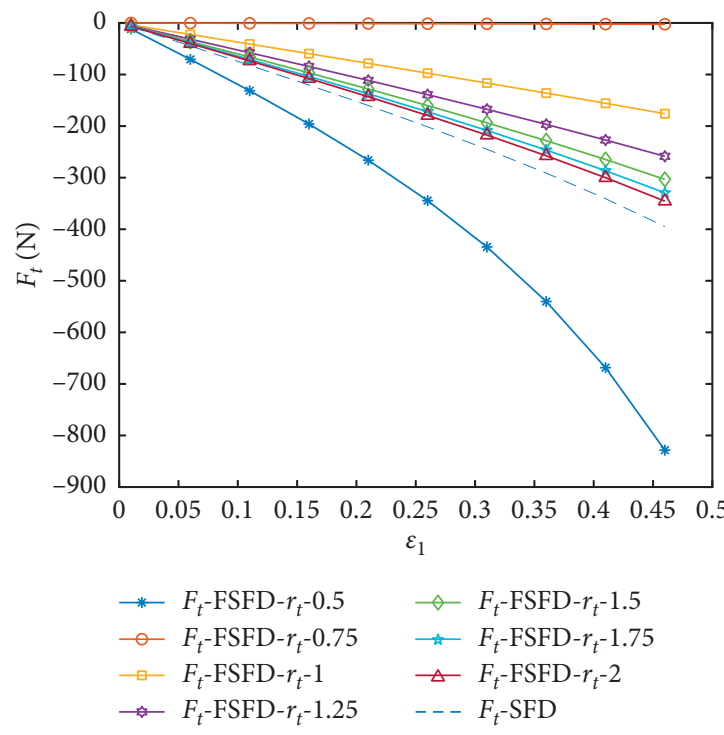

(a)

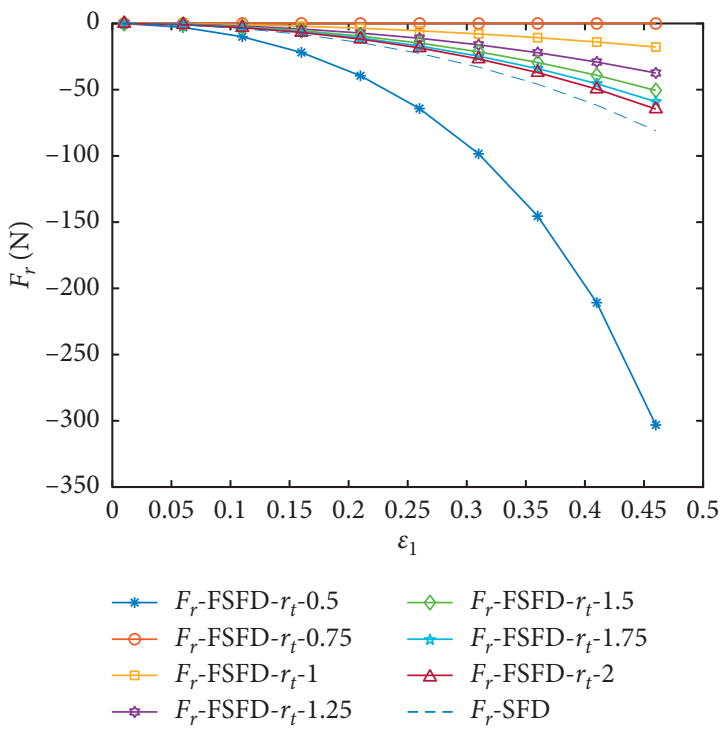

(b)

FIgURE 5: The influence of $r_{t}$ on $r_{\text {DCSFD }}$ : (a) radial film force; (b) circumferential film force.

TABLE 1: The influence of $r_{t}$ on $r_{\text {DCSFD }}$

\begin{tabular}{lll}
\hline$r_{t}$ & & Linearity \\
& $r_{\mathrm{DCSFD}}$ & $r_{\mathrm{SFD}}$ \\
\hline 0.5 & 0.9726 & \\
0.75 & 0.9998 & 0.9936 \\
1 & 0.9975 & \\
1.25 & 0.9959 & 0.9948 \\
1.5 & 0.9941 & \\
2.75 & 0.9936 & \\
\hline
\end{tabular}




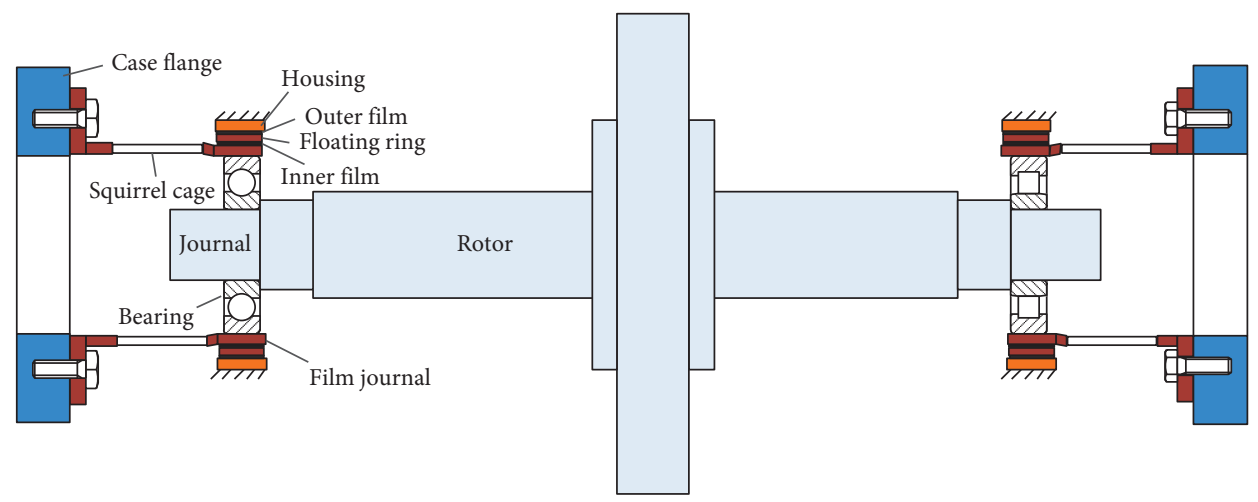

FIGURE 6: The schematic diagram of rigid rotor with squirrel cage and DCSFD.

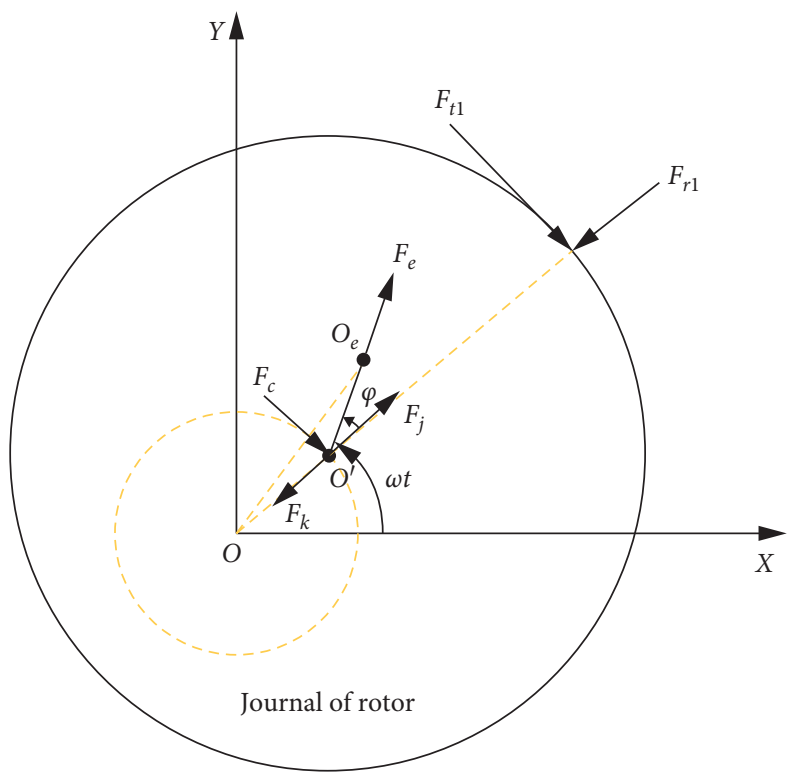

FiguRE 7: Force diagram for journal of rigid rotor.

A nondamping critical speed was defined as shown in the following equation:

$$
\omega_{c r}=\sqrt{\frac{k_{s}}{m_{j}}}
$$

The ratio of mass eccentricity to film clearance was defined as the following equation:

$$
U=\frac{e_{m}}{C_{1}}
$$

Speed parameters were defined as the following equation:

$$
\delta=\frac{\omega}{\omega_{c r}}
$$

The inner eccentricity was obtained as the following equation:

$$
\varepsilon_{1}=\frac{\delta^{2} U}{\sqrt{\left(F_{r 1} / k_{s} C_{1} \varepsilon_{1}+1-\delta^{2}\right)^{2}+\left(F_{r 1}+c C_{1} \varepsilon_{1} \omega / k_{s} C_{1} \varepsilon_{1}\right)^{2}}}
$$

where $c$ and $k_{s}$ were the structural damping and stiffness of the support, respectively.

Based on the support and rotor parameters of a real aero engine, Equation (25) could be solved numerically based on the genetic algorithm in a steady-state rotation state; with the increase in speed, the response of SFD and DCSFD is shown in Figure 8 where it is assumed that the SFD film thickness is $\mathrm{C}_{0}$.

The inner film thickness of DCSFD was $C_{1}$, and $C_{1}=0.5 C_{0}$. Take $\eta=0.45$. That is, due to convection clearance and end seal leakage, the film force loss coefficient was 0.45 and $55 \%$ of the film force was lost. 


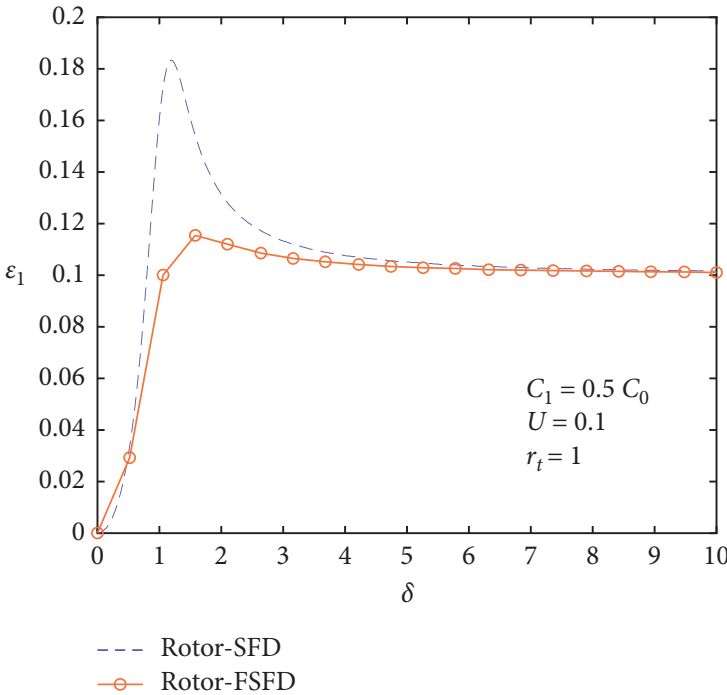

(a)

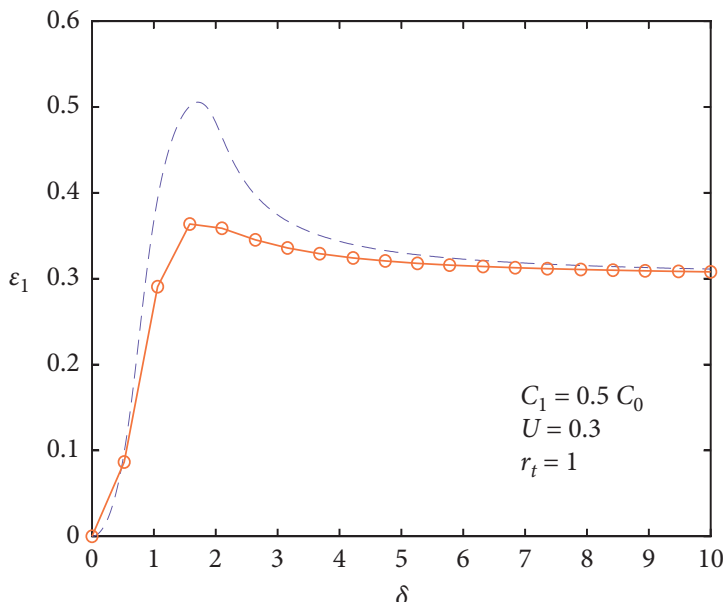

- - - Rotor-SFD

○ Rotor-FSFD

(c)

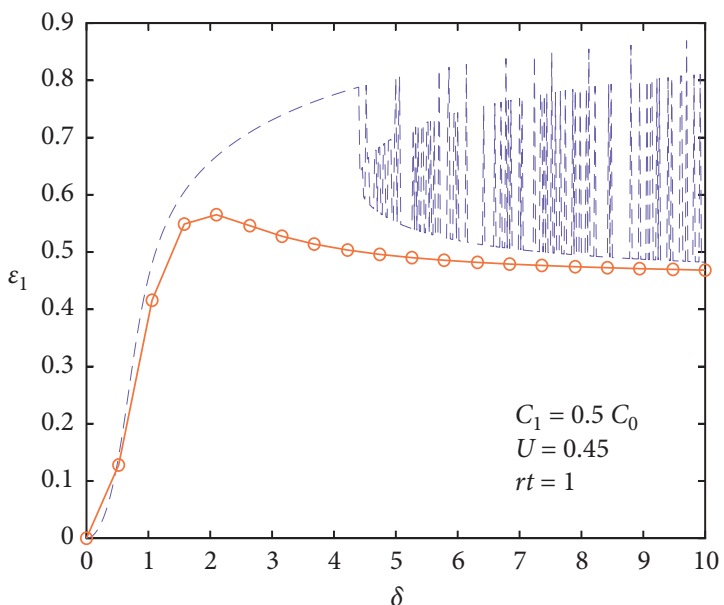

- - - Rotor-SFD

- Rotor-FSFD

(e)

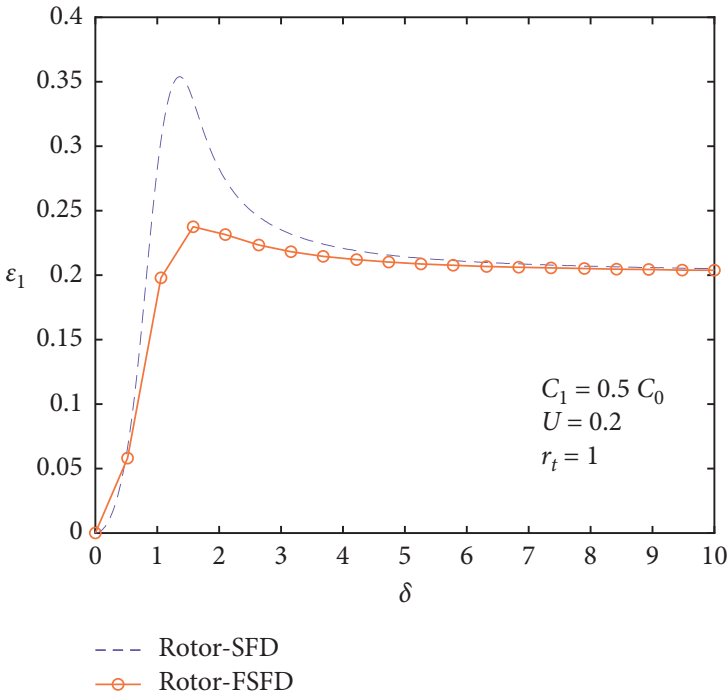

(b)

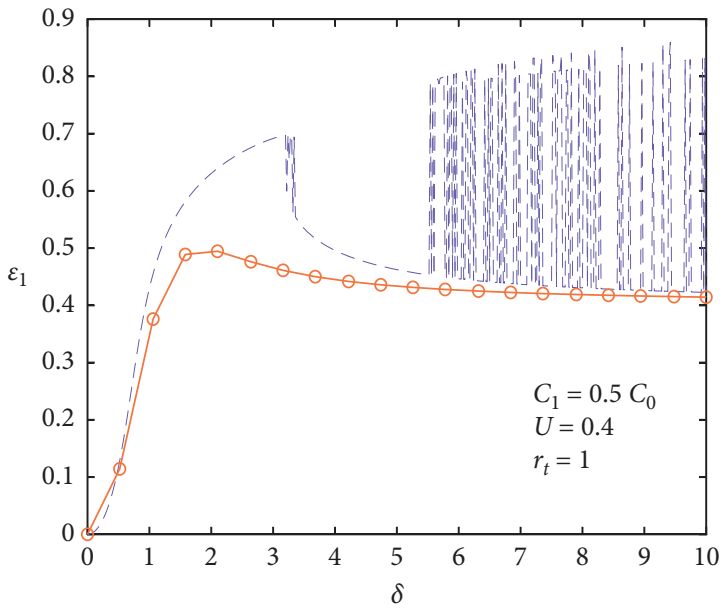

- _ - Rotor-SFD

- Rotor-FSFD

(d)

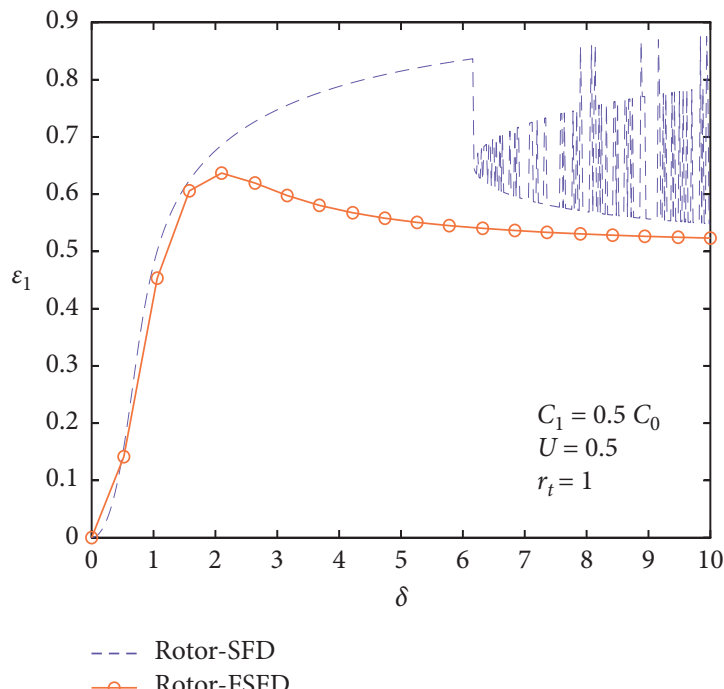

(f)

FIGURE 8: The vibration mitigation characteristic of DCSFD vs. SFD: (a) $U=0.1$; (b) $U=0.2$; (c) $U=0.3$; (d) $U=0.4$; (e) $U=0.45$; (f) $U=0.5$ 
Figure 8 shows that when $U<0.4$, the rotor rotates relatively more stable; nearby $\delta=1$, the rotor-SFD system and the rotor-DCSFD system respond to the maximum, the peak value for DCSFD was less than the SFD, and the rotor could excess critical speed more stable with DCSFD. While $U \geq 0.4$, there was a significant jump and bifurcation phenomenon in the rotor-SFD system, which indicated that there was a nonlinear enhancement of the SFD film force at this time, while the rotor was relatively stable supported on DCSFD and did not attend the nonlinear vibration phenomenon. However, what needs special explanation is that for the initial effect, the jump and bifurcation phenomenon rarely occur in the experiment and work condition of real aero engine. However, the possibility exists for the jump and bifurcation of the rotor system.

Although the DCSFD could inhibit the nonlinear vibration, it could still lead to nonlinear vibration under unreasonable design and abnormal working state.

Assumed that $C_{1}=0.5 C_{0}$ and the mass eccentricity and film force loss were all big enough that $U=0.5$ and $\eta=0.3$, Figure 9 demonstrates that while the $r_{t}=2$, the rotorDCSFD would became unstable at high rotation speed and big mass eccentricity. This conclusion was corroborated with the result above that while $r_{t}=2$, DCSFD nearly turned to be a SFD.

Assumed that $r_{t}=1.5, U=0.5$, and $\eta=0.3$, Figure 10 indicates that there is a upper limit for the inner film thickness while $r_{t}$ was out of the range $[0.75,1.25]$. In general case, the optimal range for $C_{1}$ was $0.5 \%$ o $R \leq C_{1} \leq 1.5 \%$ o $R$, while $R$ was the inner film radius of DCSFD. However, $C_{1}$ should not be bigger than $2.1 \% \cdot R$ for avoiding the nonlinear vibration.

Assumed that $C_{1}=0.5 C_{0}, U=0.5$, and $r_{t}=1.5$, Figure 11 indicates that too much pressure loss of DCSFD would lead to nonlinear vibration of the rotor-DCSFD system. In order reduce the pressure loss, the width of the convection clearance should be as small as possible and the end seal ring should have a good performance.

The above analysis manifests that the DCSFD linearity was bigger than SFD and could make the rotor system more stable at working condition, and the nonlinear vibration of the rotor system was inhibited. With a reasonable design, the DCSFD could also make the rotor-DCSFD system relatively stable at some ultimate working state.

DCSFD could not only suppress the nonlinear vibration but also suppress vibration amplitude better than SFD with a reasonable design.

When the DCSFD film force loss was relatively small, as taken in Figure 8, the internal and external film force loss was $55 \%$, and DCSFD suppresses vibration amplitude better than SFD at the critical speed. The loss of DCSFD film force mainly comes from convection clearance and end seal leakage. Figure 12(a) expresses the effect of different loss factors on the unbalanced response of the rotor-DCSFD system when $r_{t}=1$ and $C_{1}=0.5 C_{0}$.

Figure 12(a) demonstrates that the smaller the loss coefficient, the greater the film force loss, the greater the rotor unbalance response. Therefore, DCSFD's film force loss coefficient has a greater impact on rotor response. Because the loss coefficient was determined by the leakage of convection clearance and end seal, therefore, in the processable range, the smaller the convection clearance width, the better the DCSFD vibration mitigation characteristic, that is, the width of the floating ring should be as close to the film clearance width as possible; meanwhile, the performance of the end seal also has an effect on the DCSFD vibration mitigation characteristic.

When the value of $r_{t}$ and $\eta$ was determined, it is assumed that the selection of the thickness $C 1$ also has an important effect on the DCSFD vibration mitigation characteristic. Figure 12(b) shows the effects of $C_{1}$ on the unbalanced response of the rotor-DCSFD system.

Figure 12(b) indicates that the thickness of the DCSFD inner film has a great effect on the response peak of the rotor system through critical speed. The bigger the thickness of the inner film, the higher the response peak when passing through the critical speed. When $C_{1}=0.5 C_{0}$, the response peak at the critical speed was minimal. Because there is an empirical range for $C_{0}: 1 \% \cdot R \leq C_{0} \leq 3 \%$ o $\cdot R$, where $R$ is the radius of film ring, then the reasonable empirical range for $C_{1}$ is shown in the following equation:

$$
0.5 \% \cdot R<C_{0}<1.5 \% \cdot R \text {. }
$$

In summary, DCSFD could reduce the unbalanced vibration of the rotor system better than SFD and inhibit the nonlinear vibration such as jumping and bifurcation, and the essential reason is that the whirling of the floating ring adjusts the distribution of the pressure of the inner and outer film, mitigates the conflict between the journal and the film pressure, enhances the linearity of the film force, and extends the linear range of the film force.

\section{The DCSFD Film Characteristic Test}

In order to verify that DCSFD has better vibration mitigation performance than SFD, the DCSFD bidirectional excitation test rig was designed and the excitation response test was carried out based on the support components of a real aero engine.

5.1. The DCSFD Test Rig Design. Figure 13 shows the structure of the DCSFD bidirectional excitation test rig. In this paper, DCSFD and control group SFD were designed.

The floating ring floats freely in the film clearance between the journal and the housing and divides the film into two layers, the inner and the outer film. Shafts and bearings are replaced with mandrel. Aeronautical lubricant Mobile Jet Oil II was applied in this experiment. The density and viscosity are $997.5 \mathrm{~kg} / \mathrm{m} 3$ and $0.05928 \mathrm{~Pa}$.s corresponding to the oil temperature of $20^{\circ} \mathrm{C}$. The outer film pressure was measured by the Kulite microsensor mounted on the housing. The excitation force and acceleration signals are measured by the impedance head mounted at the end of the vibrators. The displacement response was available based on the acceleration signal and the steady-state excitation frequency. 


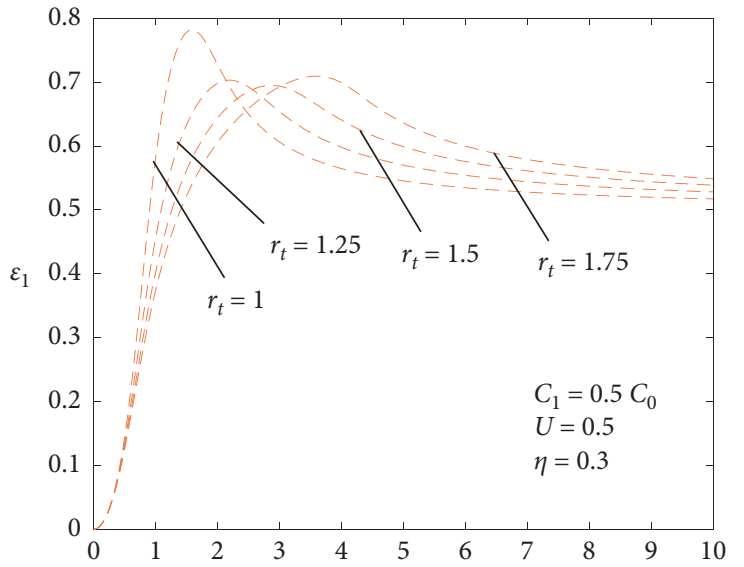

(a)

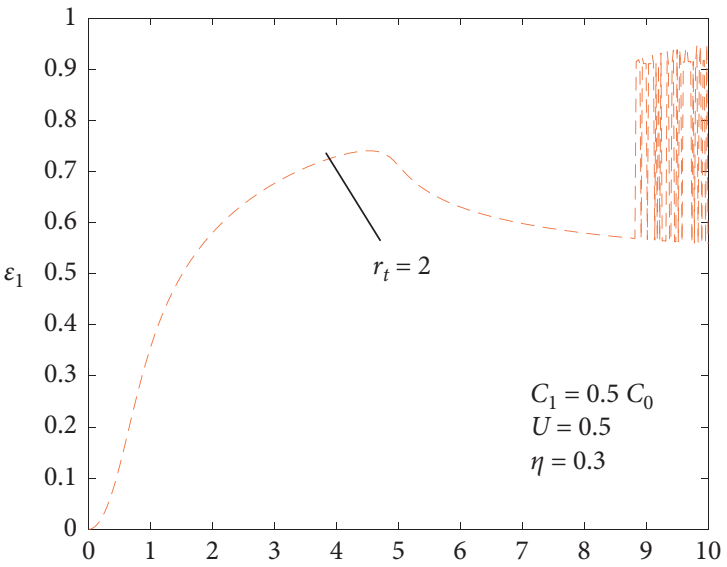

(b)

FIGURE 9: The influence of $r_{t}$ on the unbalance response of the rotor-DCSFD system: (a) stability; (b) instability.

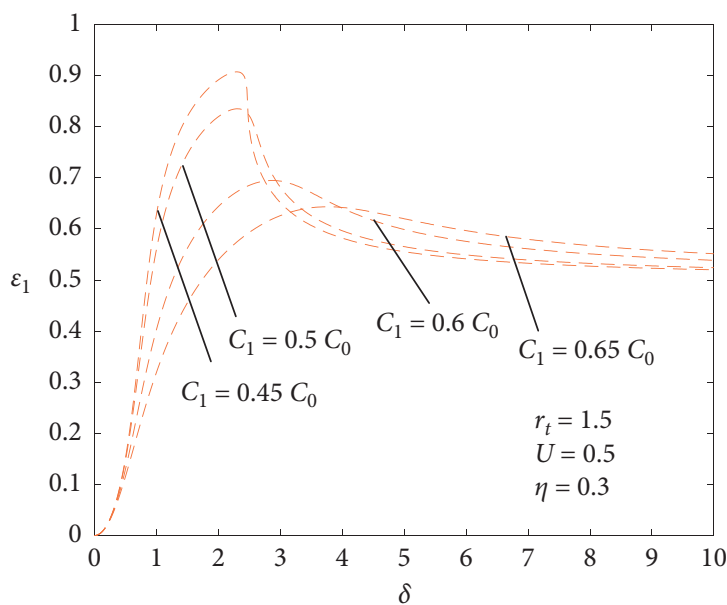

(a)

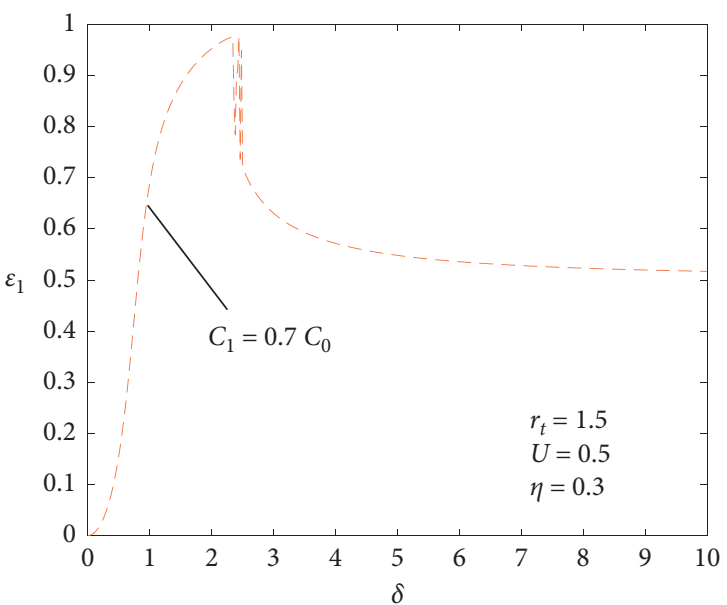

(b)

Figure 10: The influence of $C_{1}$ on the unbalance response of the rotor-DCSFD system: (a) stability; (b) instability.

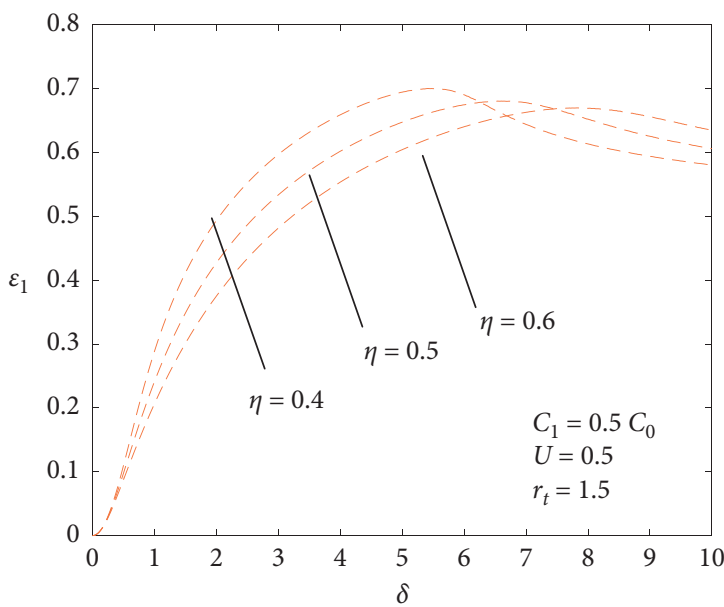

(a)

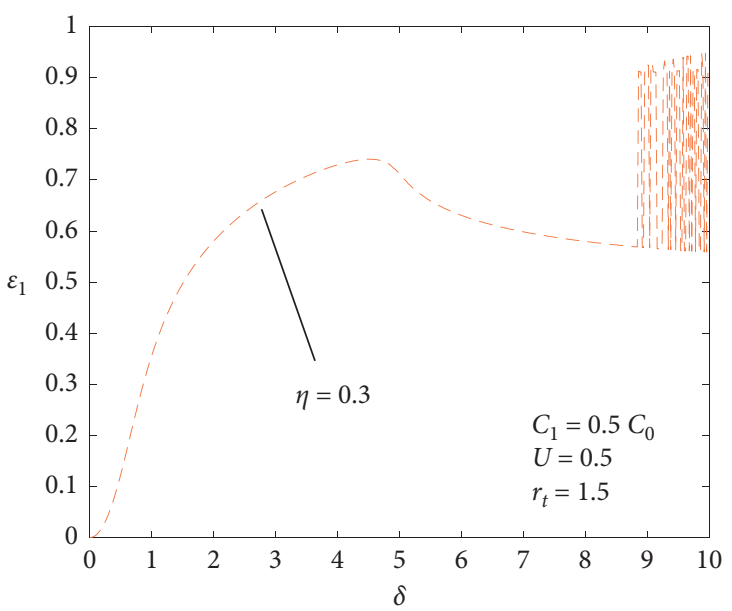

(b)

FIGURE 11: The influence of $\eta$ on the unbalance response of the rotor-DCSFD system: (a) stability; (b) instability. 


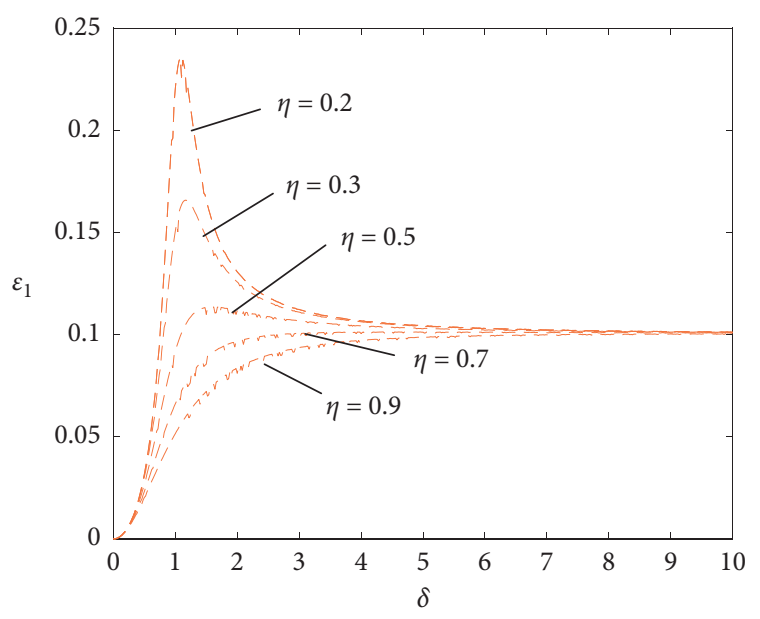

(a)

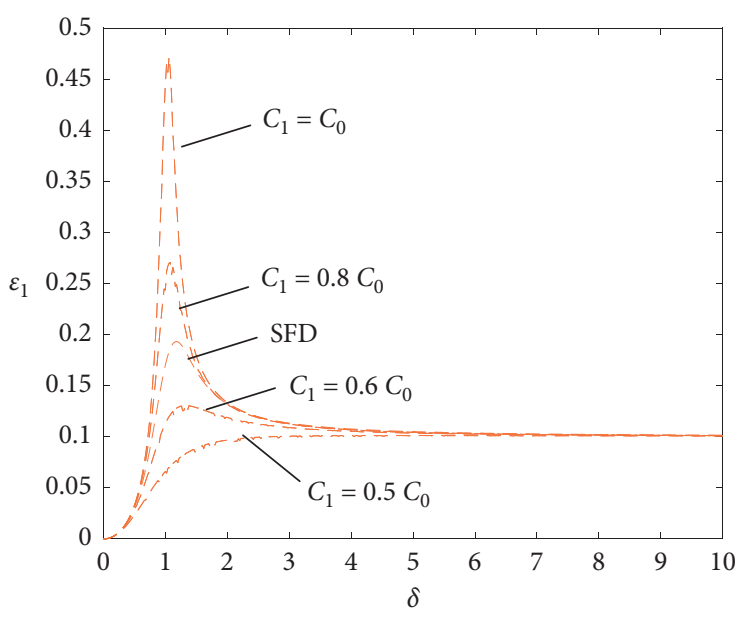

(b)

FIGURE 12: (a) The influence of $\eta$ and (b) $C_{1}$ on unbalance response of the rotor-DCSFD system.

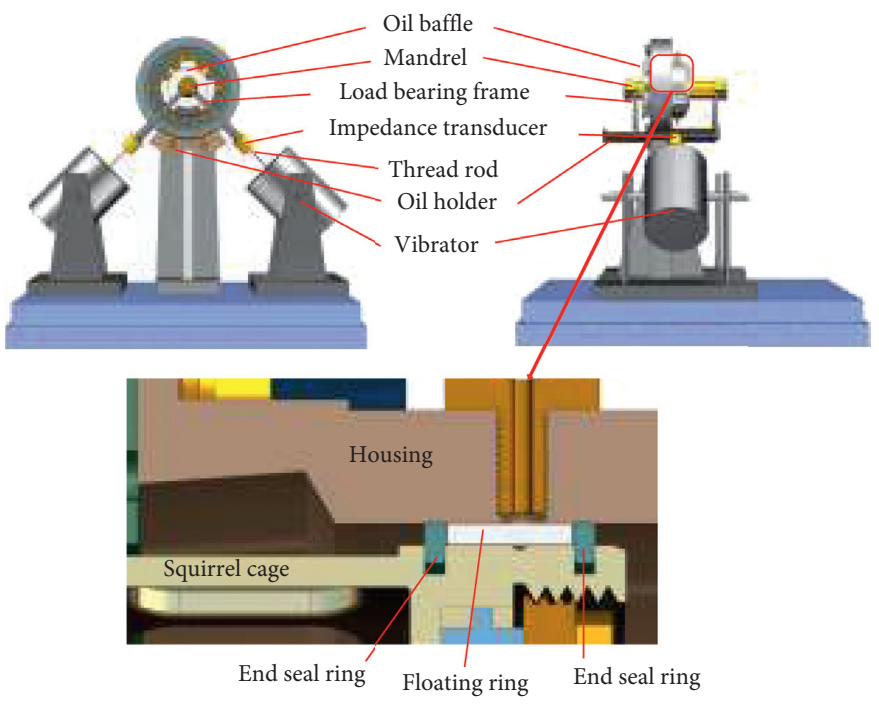

(a)
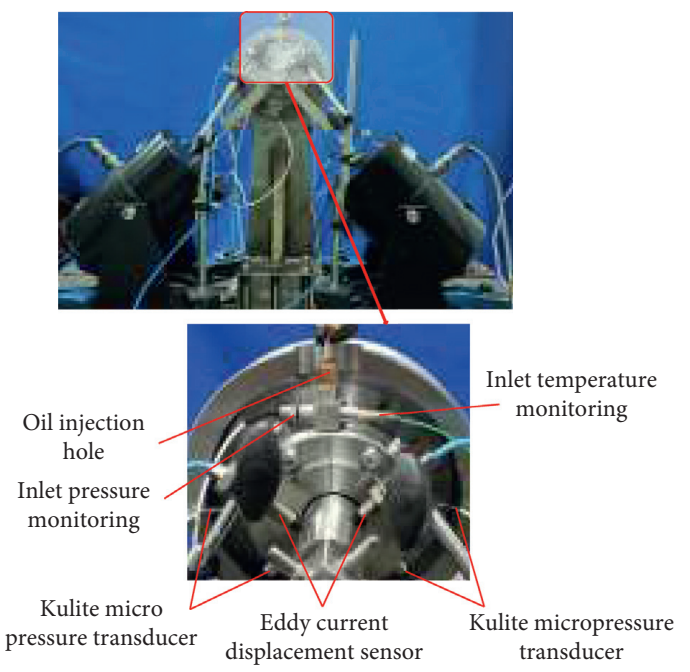

(b)

Figure 13: DCSFD bidirectional excitation test rig.

5.2. Model Verification. In the model verification test, the amplitudes of two exciting force were set $10 \mathrm{~N}$. The phase difference of the two orthogonal excitation force was $90^{\circ}$. The excitation frequency range was set as $0 \sim 400 \mathrm{HZ}$. In order to verify the simulation model, Equation (24) should be modified as Equation (27). $F_{e}$ is a constant value, and $C_{1}$ is the inner film thickness.

$$
e_{1}=\frac{F_{e} C_{1}}{\sqrt{\left(F_{r 1} / k_{s} C_{1} \varepsilon_{1}+1-\delta^{2}\right)^{2}+\left(F_{r 1}+c C_{1} \varepsilon_{1} \omega / k_{s} C_{1} \varepsilon_{1}\right)^{2}}} .
$$

The comparison between the result of experiment and the simulation is shown in Figure 14.
The unbalance response was decreased with whirling frequency while the frequency was between $0 \sim 400 \mathrm{HZ}$. The simulation results were in good agreement with the test results. The DCSFD film force model and the rotor-DCSFD model could describe the unbalanced response of real rigid rotor accurately. The conclusion based on simulation results was reliable.

5.3. The Comparison of DCSFD and SFD. The parameters of the support on both sides of the real aero engine were measured, where the damping coefficient was measured by the hammering method, and the parameters are shown in Table 2. All the lubricant parameters correspond to inlet oil temperature $20^{\circ} \mathrm{C}$. 


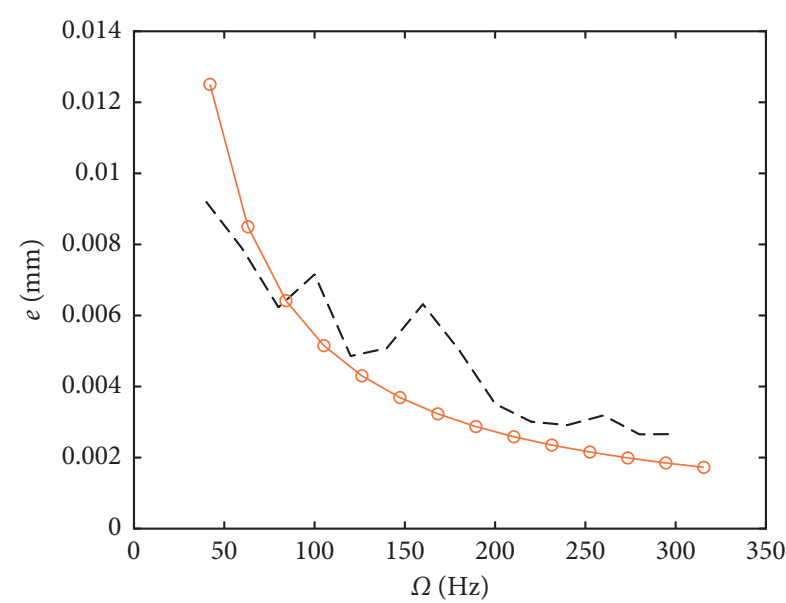

--- Experiment $\multimap$ Simulation

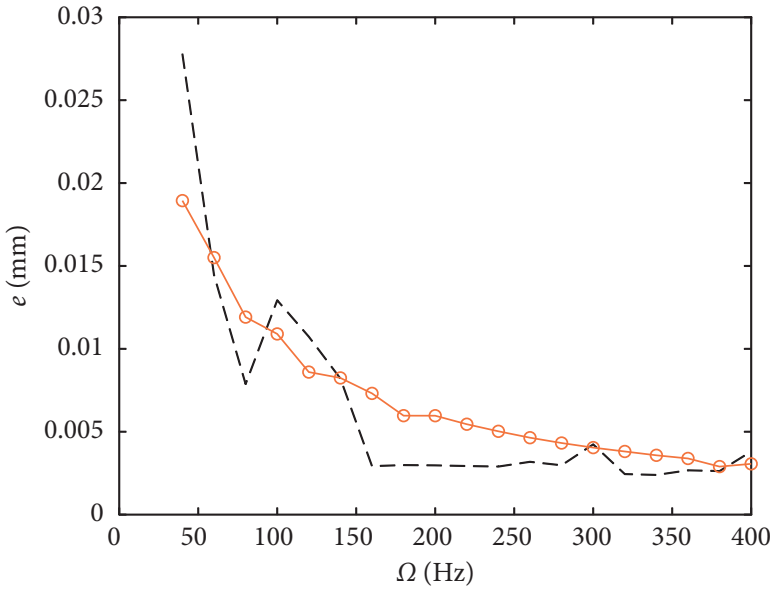

- - - Experiment

$\multimap$ Simulation

(a)

(b)

Figure 14: The result of experiment vs. simulation: (a) support 1; (b) support 2.

TABLE 2: The parameters of DCSFD test rig.

\section{Parameter}

Support 1

Support 2

Static stiffness $\left(\times 10^{7} \mathrm{~N} / \mathrm{m}\right)$

Damping $(\mathrm{N} / \mathrm{m} / \mathrm{s})$

2.4

3.44

Mass of journal $(\mathrm{kg})$

816

Width of film clearance $(\mathrm{mm})$

2

1.95

Thickness of film clearance $(\mathrm{mm})$

12.5

9.8

Thickness of SFD film clearance $(\mathrm{mm})$

0.06

0.11

Width of floating ring $(\mathrm{mm})$

0.06

Film thickness ratio: $r_{t}$

Force amplitude (N)
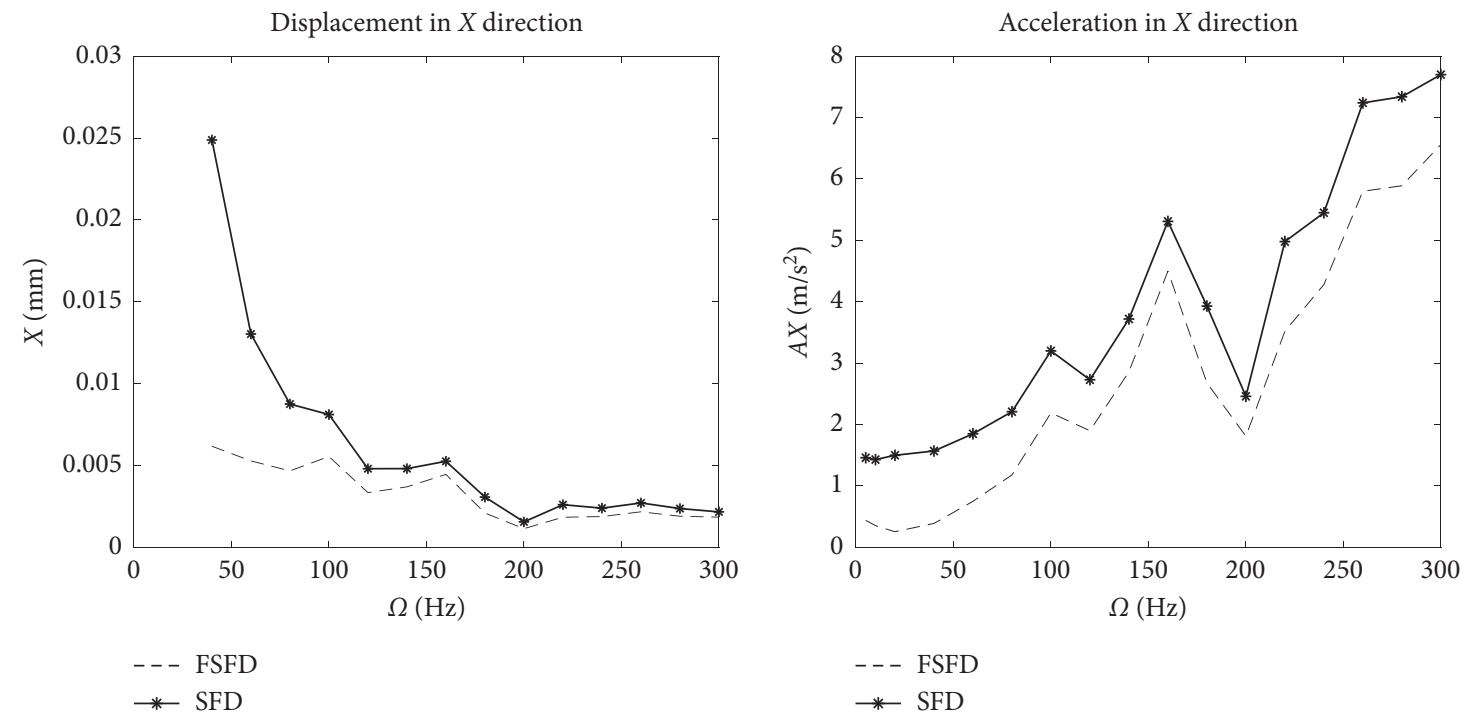

(a)

(b)

Figure 15: Continued. 


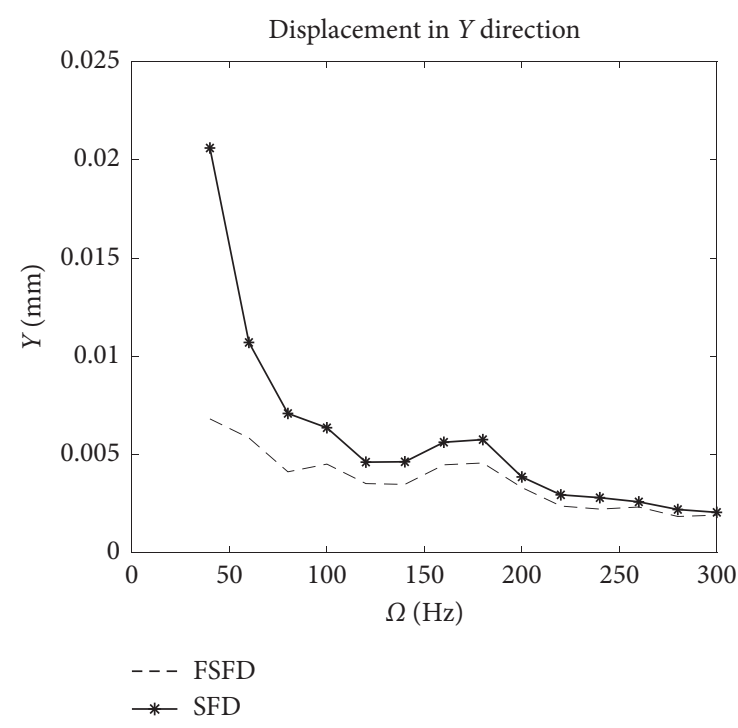

(c)

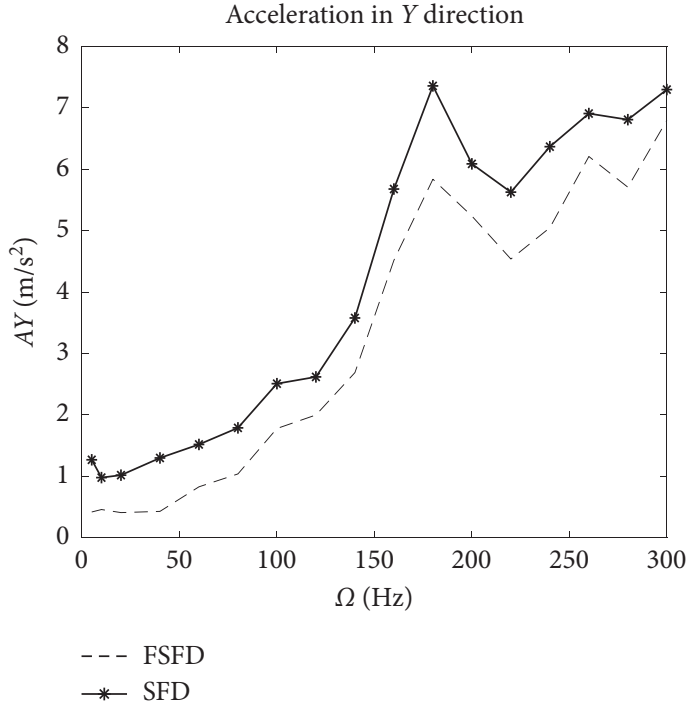

(d)

FIGURe 15: DCSFD vs. SFD for support 1: (a) X directional displacement; (b) X directional acceleration; (c) Y directional displacement; (d) Y directional acceleration.

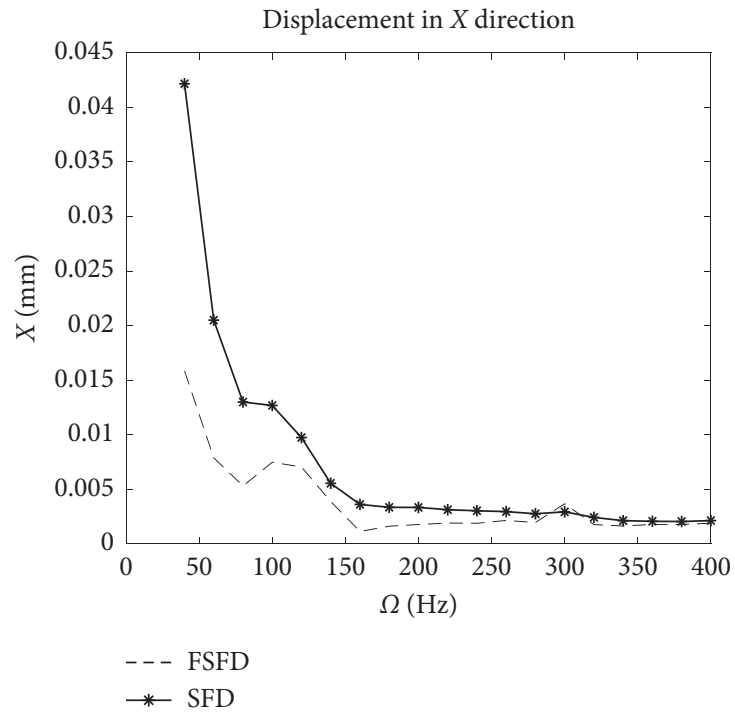

(a)

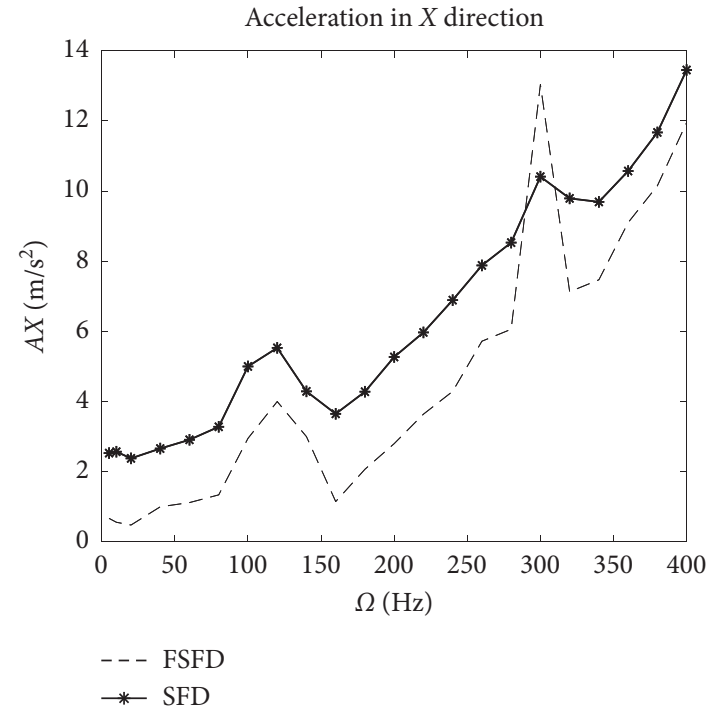

(b)

FIgURE 16: Continued. 


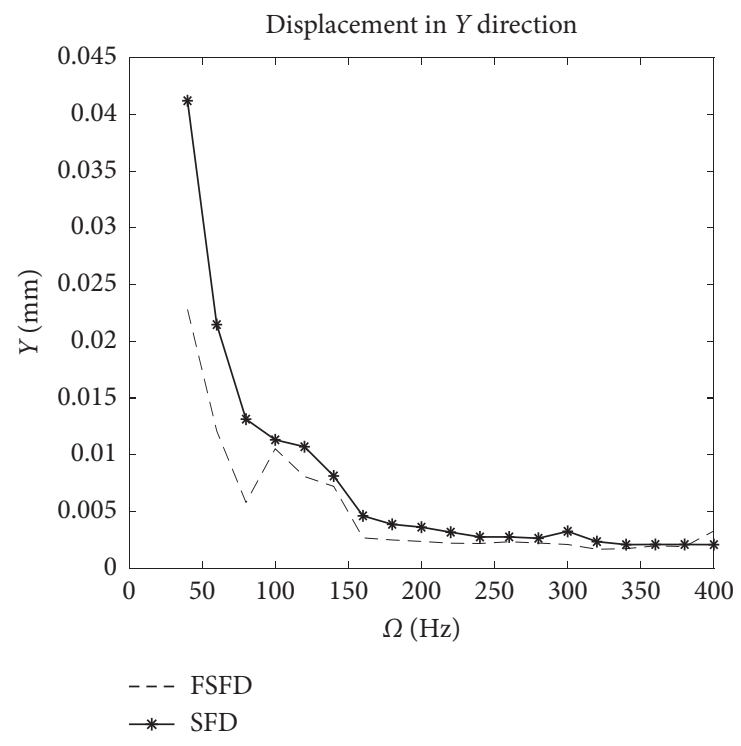

(c)

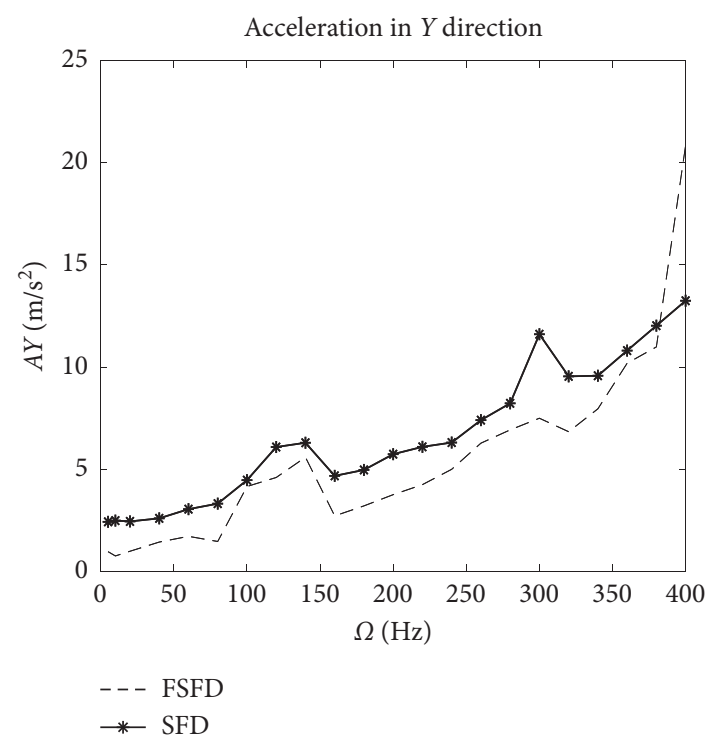

(d)

FIGURE 16: DCSFD vs. SFD for support 2: (a) X directional displacement; (b) X directional acceleration; (c) Y directional displacement; (d) Y directional acceleration.

For support 1 and support 2, respectively, when installing DCSFD and SFD, the response results of the journal are shown in Figures 15 and 16. The test result indicated that when the DCSFD was installed, the response of the journal was less than that of the SFD at nearly all the vibration frequencies. With the whirling of the floating ring, the energy of the journal whirling was absorbed by the floating ring. The comparison of acceleration signal demonstrates that the transmitted force from the journal was reduced for floating ring whirling. The difference of the transmitted force between the SFD and DCSFD basically kept constant with increase in whirling frequency of journal. Chen concluded that reasonable combination of parameters could help the rotor-SFD system to avoid the harmful nonlinear vibration [22]. The whirling of the floating ring could regulate the inner and outer film pressure and reduce the difference of film stiffness in different directions. In this way, DCSFD could help the rotor system avoid the harmful nonlinear vibration.

DCSFD has better vibration absorption characteristic than SFD, and the whirling of floating ring could absorb the energy transmitted from the journal. This conclusion received a good consistence with the simulation result.

\section{Conclusion}

In this paper, a novel model of DCSFD was established and a dynamic model of the rigid rotor-DCSFD system was constructed. The concept of the linearity of the film force of DCSFD was proposed. The relationship between eccentricity of the inner and outer film and the relative eccentricity was constructed. The vibration attenuation characteristic of DCSFD was researched and compared with that of SFD. The vibration mitigation characteristic of DCSFD was investigated. The model was verified by DCSFD excitation response experiment, and the vibration mitigation characteristics of DCSFD and SFD were compared by the tested result. The conclusions were drawn as follows:

(1) There is approximate linear correlation between eccentricities of inner and outer film of DCSFD. The slope was influenced greatly by the thickness ratio of the inner and outer film.

(2) The DCSFD film thickness ratio should be maintained at $0.75 \leq r_{t} \leq 1.25$; in the reasonable DCSFD film thickness ratio range, DCSFD film force linearity was better than SFD.

(3) The optimal range for $C_{1}$ was $0.5 \% \cdot R \leq C_{1} \leq 1.5 \%$. $R$. $C_{1}$ should not be bigger than $2.1 \% \cdot R$ for avoiding the nonlinear vibration.

(4) The DCSFD loss coefficient has a great influence on the response peak of the rotor system through critical speed, the smaller the film force loss, the lower the rotor response peak, which requires the width of the floating ring to be as close as possible to the width of the film clearance within the scope of the processing technology, and the end seal was required to have a good oil sealing effect, as far as possible without loss of film force.

(5) Under reasonable design, DCSFD could reduce the unbalance response peak at critical speed and suppress the nonlinear vibration such as jumping and bifurcation. The rotor-DCSFD system could remain stable in some limit working state such as big mass eccentricity. The inner film thickness and pressure loss coefficient have great influence on DCSFD 
performance of suppressing the nonlinear vibration at the limit working sate.

Gyroscopic moment has a great effect to the dynamic characteristic of the flexible rotor system. However, gyroscopic moment was neglected in the rigid rotor system. We believe vibration mitigation characteristic of DCSFD could be researched more deeply while the flexible rotor supported on DCSFD could be modeled and analyzed. Further research was needed to study the vibration mitigation characteristic of DCSFD.

\section{Data Availability}

The data, models, or code generated or used during the study are available from the corresponding author by request.

\section{Conflicts of Interest}

The authors declare that they have no conflicts of interest.

\section{Acknowledgments}

The authors thank the National Natural Science Foundation of China (fund serial number 51775266), the National Planned Major S\&T Project (project number 2017-IV-00080045), and the Key Laboratory of Aero Engine Vibration Technology of Aero Engine Corporation of China for their support.

\section{References}

[1] J. A. Friedericy, R. T. Eppink, Y. N. Liu, and A. Cetiner, An Investigation of the Behavior of Floating Ring Dampers and the Dynamics of Hypercritical Shafts on Flexible Supports, U.S.Army Aviation Materiel Laboratories Fort EustisVirginia, Eustis, Virginia, 1965.

[2] D. P. Fleming, "Dual clearance squeeze film damper for high load conditions," Journal of Tribology, vol. 107, no. 2, pp. 274-278, 1985.

[3] P. David, Fleming. Dual Clearance Squeeze Film Damper for High Load Conditions [R], Lewis Research Center, Cleveland, OH, USA, 1984.

[4] Dual clearance squeeze film damper, US., 4527910, Jul.9, 1985.

[5] L. Moraru, T. G. Keith, F. Dimofte, S. Cioc, and D. P. Fleming, "Dynamic modeling of a dual clearance squeeze film damperPart I: test rig and dynamic model with one damper," Tribology Transactions, vol. 46, no. 2, pp. 170-178, 2003.

[6] L. Moraru, F. Dimofte, S. Cioc et al., "Dynamic modeling of a dual clearance squeeze film damper," in Proceedings of the World Tribology Congress III, Torino, Italy, December 2005.

[7] L. Moraru, T. G. Keith, F. Dimofte et al., "A study of a dual clearance squeeze film damper northern trust," 2009.

[8] B. H. Ertas, M. Camatti, and G. Mariotti, "Synchronous response to rotor imbalance using a damped gas bearing," Journal of Engineering for Gas Turbines and Power, vol. 25, 2009.

[9] R. Ma and E. J. Hahn, "Floating ring squeeze film damper: theoretical analysis," Tribology International, vol. 33, no. 3-4, pp. 249-258, 2000.

[10] H. Zhou, G. Luo, G. Chen, and F. Wang, Dynamic Response Analysis of Rotor Supported on Floating Ring Squeeze Film dampers, Nanjing University of Aeronautics and Astronautics, Nanjing, China, (In Chinese), 2013.

[11] H.-L. Zhou, G.-H. Luo, G. Chen, and F. Wang, "Analysis of the nonlinear dynamic response of a rotor supported on ball bearings with floating-ring squeeze film dampers," Mechanism and Machine Theory, vol. 59, no. 4, pp. 65-77, 2013.

[12] H. L. Zhou, G. H. Luo, G. Chen, and H. T. Tian, "Two dynamic models of dual clearance squeeze film damper and their verificationfilm damper and their verification," Tribology International, vol. 66, no. 2013, pp. 187-193, 2013.

[13] J. Sung-Hwa, L. San Andres, and G. Bradley, "Forced coefficients for a short length,open ends squeeze film damper with end grooves:experiments and predictions," Journal of Engineering for Gas Turbines and Power, vol. 138, no. 2, Article ID 022501, 2016.

[14] J. Wang, "Dynamic Analysis and optimization design of the SFD-sliding bearing flexible rotor system," Journal of Theoretical and Applied Information Technology, vol. 48, no. 1, pp. 163-167, 2013.

[15] M. Irannejad and A. Ohadi, "Vibration analysis of a rotor supported on magnetorheological squeeze film damper with short bearing approximation: a contrast between short and long bearing approximations," Journal of Vibration and Control, vol. 23, no. 11, pp. 1792-1808, 2017.

[16] G. Creci, J. Orlando Balastrero, S. Domingues, J. C. Menezes et al., "Influence of the radial clearance of a squeeze film damper on the vibratory behavior of a single spool gas turbine designed for unmanned aerial vehicle application," Shock and Vibration, vol. 2, 2017.

[17] J. Zapomel, P. Ferfecki, and P. Forte, "Vibrations attenuation of a Jeffcott rotor by application of a new mathematical model of a magnetorheological squeeze film damper based on a bilinear oil representation," Acta Mechanica, vol. 230, pp. 1625-1640, 2019.

[18] Z. Luo, J. Wang, R. Tang, and D. Wang, "Research on vibration performance of the nonlinear combined supportflexible rotor system," Nonlinear Dynamics, vol. 98, no. 1, pp. 113-128, 2019.

[19] G. Adiletta, "Bifurcating behaviour of a rotor on two-lobe wave squeeze film damper," Tribology International, vol. 92, no. 2015 , pp. $72-83,2015$.

[20] G. Adiletta, "An insight into the dynamics of a rigid rotor on two-lobe wave squeeze film damper," Tribology International, vol. 116, pp. 69-83, 2017.

[21] L. Yan, M. Liao, S. Wang, Z. Lu et al., "Effect of squeeze film damper concentricity and rrbhing on rotor visration characteristics," Journal of Vibration and Shock, vol. 39, no. 1, pp. 69-83, 2020, (in Chinese).

[22] H. Chen, L. Hou, and Y. Chen, "Bifurcation analysis of a rigidrotor squeeze film damper system with unsymmetrical stiffness supports," Archive of Applied Mechanics, vol. 87, no. 8, pp. 1347-1364, 2017.

[23] J. I. Inayat-Hussain, "Bifurcations in the response of a flexible rotor in squeeze-film dampers with retainer springs," Chaos, Solitons \& Fractals, vol. 39, no. 2, pp. 519-532, 2009.

[24] A. Delgado and L. San Andres, "Identification of force coefficients in a squeeze film damper with a mechanical seal: large contact force," Journal of Tribology, vol. 132, Article ID 032201, 2010.

[25] A. Bouzidane and M. Thomas, "Nonlinear dynamic analysis of a rigid rotor supported by a three-pad hydrostatic squeeze film dampers," Tribology Transactions, vol. 56, no. 5, pp. 717-727, 2013. 
[26] A. Bouzidane and M. Thomas, "Nonlinear dynamic behavior of a flexible shaft supported by a smart hydrostatic squeeze film damper," Journal of Tribology, vol. 135, no. 3, Article ID 031701, 2013.

[27] P. Bonello and H. Pham, "A theoretical and experimental investigation of the dynamic response of a squeeze-film damped twin-shaft test rig," Journal of Mechanical Engineering Science, vol. 228, no. 2, pp. 218-229, 2014.

[28] B. Aydin, "Numerical continuation applied to nonlinear rotor dynamics," Procedia Lutam, vol. 19, pp. 255-265, 2016.

[29] L. Zhao, M. Liao, and J. Niu, "Investigation on steady state unbalance response of rotor with elastic ring squeeze film damper," IOP Conference Series Materials Ence and Engineering, vol. 751, Article ID 012043, 2020. 